\title{
Practice and Cognition to Strengthen College Students' Moral Education
}

\author{
Wanbin Ren \\ Dezhou University, Dezhou 253023, China \\ Tel: 86-534-8985-768Ｅ-mail: rwb@dzu.edu.cn
}

\begin{abstract}
College students' ideological morality always is the hotspot concerned by various circles of the society, and to strengthen and improve the ideological and moral education in colleges, continually enhance the pertinence and actual effect of the moral education, help college students to dissolve their worldly confusion in moral culture, further enhance their moral level and make them become eligible socialism successors with cultures and morality, needs mutual endeavors from society, colleges, families and students themselves.
\end{abstract}

Keywords: College students, Moral education

\section{Actuality of modern college students' total morality}

Every one has his moral base line and the influence of the external moral environment on the individual morality can not be ignored, but individual moral deviation will not influence the enhancement and construction of the whole moral level. College students are excellent young students though various knowledge selection and moral evaluations, and most of them have accepted good family education and school education, and they have basic moral quality. With the increase of their ages and the enhancement of their scientific and cultural level, their cognition ability and self-morality to the society have been strengthened, and strong responsible consciousness and talent consciousness continually encourage them to study the professional knowledge hard and try to perfect their own personalities. The special human environment of the college provides conditions for college students' healthy growth, and the education concept imparting knowledge and educating people and the teachers' morality continually enhancing build the barriers to resist bad moral influences for college students, and add their strengths to continually enhance their morality. The practices of the moral education in recent years indicate that modern college students are anxious for knowledge, want to become useful persons, and would like to contribute their intelligences for the nation and society. They have courtesy and honesty, and they observe disciplines and obey laws, and they are rich in love and aggressiveness, and their whole morality is good, and the moral level is high. Of course, we can not deny some individuals' moral deviation and demoralization, and these anomic individuals have produced destructive influences to the moral education. To fully cognize the existence of these problems and try to explore corresponding solutions can further enhance and improve the moral education works for colleges, and to only aggrandize these influences or deny the existing results of the moral education can only produce negative effect to the future moral education.

\section{Rational analysis of college students' moral deviations}

In modern college students' growth process, they will encounter many confusions and challenges, and the behavior deviation even the out-of-control induced by the moral confusion is most concerned and worried by the public. The relative reasons should be found from college students themselves and their exterior environment. The modern college students are in the transition period of the society, and in this period, the whole core value view of the society has certain uncertainty, and some moral rules which have been accepted by most people for a long time are broken, but new moral rules have not been confirmed completely. In this social environment, the moral confusions existing in teachers and students are inevitable. The formation of human value concept and moral quality is realized by two kinds of mechanism including social modeling and individual learning, and their development status always depend on the degree that their vital interests are realized. At present, most colleges emphasize students' moral education, and have done large numerous of effective works, but because of the influences and limitations from subjective cognition, work methods and various objective conditions, the effect is not entirely satisfactory. Many problems such as psychology, learning, employment and poor student surrounding college students have not been completely solved, and individual students lack in sufficient cognitions to the moral education and loosen their self moral requirements because of their inertia mentality, which induces the fuzzy cognition to the moral selection diversification and moral value judgment, and differences occur between the moral cognition and moral behavior, and knowledge, feeling, will and behaviors can not effectively unified, and the double standards about the moral requirement and moral evaluation are produced, i.e. the moral confusion requiring others in the mainstream and requiring him in the popular. There are many factors to produce the moral confusion, and the existence of the moral confusion is adverse to students' growth, which makes students lack in self-examination and self-control, and will finally induce the moral deviation. Though some students don't admit that they have moral confusion, and won't accept moral education and self-morality culture, but it is not obviously enough to depend on a little simple moral base to reply continually developing moral requirements. 


\section{Resolving college students' doubts in the moral education}

The formation of college students' morality must transverse a long-term complex process, and it needs helping college students to eliminate moral confusion from all directions and layers. The whole society should exactly grasp students' individual characters, fully exert education functions of society, college and family, try to mobilize college students' enthusiasm of self-improvement, really implement the moral education into various aspects in the education and teaching, and help them to go out from the shadow of the moral confusion.

Firstly, the social moral environment is very important for the college students' moral formation, and good moral environment is the base for college students to become useful persons. Student enrollments always will return to the society, and they need to know the society, and hope the society will give them good moral supports, and want to use their own good moral quality to influence the society. However, their moral ideals are often broken by the astringent reality, and many bad social memories often make them loss their direction and their rough experiences to apply for a job also make them to suspect their own values. To dissolve the moral confusion from the society, two aspects including the social environment and college students should be considered. On the one hand, the social practice of college student moral education should be strengthened, and the colleges should further enhance college students' social cognition ability and moral evaluation ability, and combine traditional moral education with the moral innovational education, and unify individual moral ideal with social moral requirements, lead students to actively perform self-education and self-improvement, and correctly face the existence of moral confusion, and scientifically analyze the reasons of moral confusion, and actively dissolve various moral conflicts in the social development. On the other hand, the social moral environment should be further optimized, the influences of bad mood in the society on college students should be eliminated, and the scientific morality evaluation system should be established. College students are in the middle phase of youth growth, and they have deficient moral cognition ability and lack in deserved education, which will make them get into the moral confusion. They also pay more attention to the moral requirements and moral evaluations from the society, and the public always thought college students are outstanding persons of the time and require higher standards for them. Individual moral deviation will be regarded as the drop of the whole quality, which is not scientific obviously. The society should exactly evaluate the moral actuality of college students, objectively treat the moral deviations, and really embody the responsibility consciousness and function of the society for the college students' moral education, which is the key to enhance college students' moral level and the important approach to help them go out from the moral confusion.

Secondly, the school education is the key stage for the growth of college students, and the base point to realize their moral ideals. When the so-called "worldly ideal", college entrance examination, is realized, many college students will loss their targets and drives, and they also suspect their own self-orientation in the social reality with increasingly drastic competition. The colorful world has made them be stranded, and whether they pursue ideals or common customs facing truth and money also make them have heavy suspicion. The occurrences of college students' life confusion or conflict mentality are not occasional, and the reasons exist in not only students but college education. The essential of moral confusion is the suspicion of ideal and faith and the loss of life value, which is presented not only by the weakness of the ideal and faith education in colleges, but by students' demands for the life value education. To dissolve college students' growth confusion radically, the moral education actuality must be reflected. First, the relativism of moral education weakens the contents of moral education, and the impartation of practical knowledge replaces the edification of moral personality and weakens the influences of moral education. Second, the political liability of moral education deviates from the essential of moral education, and the political education replaces the moral education and influences the effect of moral education. Third, old education method breaches students' growth rule and the forming rule of moral quality, and students loss learning interests and generate the inertia of self-improvement. Fourth, the lagged moral education management system makes moral educators dissolve in common public and get away from the responsibility of moral education, and students lose examples and direction. To try to eliminate various disadvantages of moral education is the premise and base to develop the moral education, and to continually explore scientific education method is the important measure to enhance the moral level. The moral education needs good environment, teachers with good quality and scientific education method. To establish and perfect the guarantee system of moral education, further strengthen all teachers' moral consciousness, make moral education near actuality and life go into the classroom and students are very important to comprehensively enhance the whole education and teaching level for colleges.

Thirdly, the family education is the base to form college students' morality, and the important part of the moral education. College students' basic morality comes from family, but a few moral confusion also come form family, and the civilized family education is the activator of college students' healthy growth, and the conflicts in family will easily produce moral confusion. It is very important to fully utilize the influence of family education and actively exert parents' function in moral education for enhancing the pertinence and actual effect of college moral education. First, the special identity of parents decide their unique position in moral education, and in some aspects, they more understand students than teachers, and know the sticking point of the conflict, and more easily find out the breakthrough point to solve problems. For example, for the idea confusion and moral confusion induced by family accident and poverty, parents have more confidences to solve these problems. Second, the family's affection enhances the appetence of 
education. Parents and family depend on each other and trust each other, and they can achieve consensus more easily. Third, college students' gratitude consciousness strengthens the persuasion and centripetal force of education. College students are the hope of the family, and their growth can not leave the care and help from colleges and society, and parents' painstaking efforts and sweats, and they want to become useful persons to redound upon colleges and society, and they would like to use excellent achievements and good moral quality to redound upon their parents. Fourth, parents' model function is always the complex that college students can get rid of. Every one's moral cultivation can not leave parents' education and cultivation, and good family education is the base of college students' growth, and excellent parents are the models for them to learn. The family education is the important part of the education, and it is the essential requirements of carrying out educating people by all society, from all directions and in all processes to fully exert the assistant function of family education in college students' moral education. However, college students' moral education is always obligatory responsibility of college, and to emphasize the function of family education and parents' educational obligation can not draw a forced analogy, but concretely analyze concrete problems. At the same time, the negative effect possibly produced by family education should be clearly realized, and good family education has active meaning for college students' growth, and parents' bad moral influence is the forcing house to produce moral confusion.

Fourthly, to strengthen self-improvement is the key to enhance the moral level. The moral self-improvement means college students' self-education and self-construction of morality according to social requirements, and it is the key to enhance the moral level and realize moral ideal for college students. The education without self-education is unsuccessful education, and in the same way, the morality construction without self-improvement can not achieve the intention of education. The moral education can exert its deserved function only when students' interior drive of self-improvement is inspired. Traditional moral education mode ignores students' subject status, breaches the rules of moral cultivation, lose good education opportunity, and influence students' healthy growth because it over emphasizes educators' leading function, which should be highly concerned by educators. The process of self-education and self-improvement is a complex process, and not all people pay more attention to self-education, and not all college students can actively strengthen their morality improvement. Educators' responsibility is to lead college students to actively participate in various moral education activities through their educational influences, and continually enhance the enthusiasm and consciousness of morality improvement. There are many methods to improve students' moral cultivation same as wrong regions, and it is the key of enhancing educational effect to continually enhance the scientific character and reduce the blindness of the education method. In practice, the society should emphasize not only the drive function of educational encouragement, but also the affection function of personality power, and the society should not only pay attention to the supervision function of morality evaluation, but fully exert the active meaning of self-control. The college should organically combine classroom education with social moral practices, actively develop moral evaluations through usual moral practices, instruct college students' self-moral consideration, continually enhance the responsible consciousness of self-improvement, and further strengthen the consciousness of becoming useful persons. The time that college students accept college education is limited, and the time of self-education and self-improvement is long. To fully exert the subject function of moral education has deep influences for college students' healthy growth and lifelong education.

\section{Conclusions}

College students are the future of the nation and the hope of the nationality, and they are the new force to realize the project of the socialist modernized construction. The moral education and the moral construction are the key to improve students' growth, and they are the important part in the quality education, the essential requirement to construct the harmonious society, and the hope project to ensure worthy successors to construct the socialist cause. The growth of college students is flexuous and the formation of the morality is complex, so the whole society should fully mobilize various powers from society, family and college to participate in the moral education, try to enhance college students' enthusiasm about self-improvement, and really take college students' basic moral education, moral accomplishment education and moral enhancement education as one integrated system to develop, and it is the duty-bound responsibility to cultivate socialist eligible successor with cultures and morality for the whole society. The social development varies from minute to minute, and the moral education still shoulders heavy responsibilities.

\section{References}

Chen, Yungui. (2002). Research of the Actual Effect of Moral Education for College Students. Journal of West Anhui University. No.6.

Du, Jiangfeng. (1997). The Moral Education of College Students. Social Sciences Journal of Colleges of Shanxi. No.2.

Lv, Fei. (2007). Moral Deviation and Navigation of Contemporary University Students. Journal of Anhui Radio \& TV University. No.2.

Yue, Yili \& Cai, Yumei. (2005). Moral Education in Colleges. China Science and Technology Information. No.15.

Zhang, Xuezhong \& Fu, Caiyun. (2004). Study on the Moral Education Mode for College Students. Inner Mongolia Statistics. No.6. 